
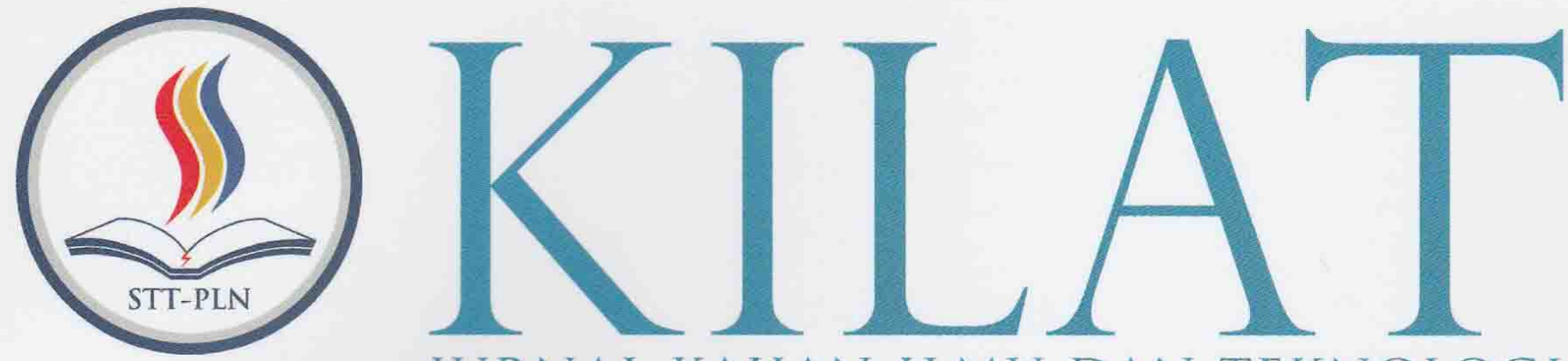

JURNAL KAJIAN ILMU DAN TEKNOLOGI

Endah Lestari: Irma Wirantina K: Ranti Hidayawanti

Faisal:

Muhammad Ridwan: Mardawati

Gita Puspa Artiani: Indah Handayasari

Kresna Ramanda; Irmawati Carolina

Ratna Mutu Manikam:

Farid Setiawan

Rayung Wulan

Roni Kartika Pramuyanti

Rr. Mekar Ageng Kinasti; Djoko Nugroho Notodisuryo

Satria;

Ayu Setiawati Agustini

Syam Gunawan: Pritasari Palupiningsih

Ali Ridho Gumelar: Anton: Ummu Radiyah

M. Yoga Distra Sudirman: Yessy Fitriani
ANALISA TAMAN ATAP DALAM UPAYA MENGURANGI LIMPASAN AIR HUJAN PADA BANGUNAN PERKOTAAN

OPTIMASI DIAGRAM LAYANAN PEMBELIAN DALAM MENDUKUNG MANAJEMEN HUBUNGAN PELANGGAN

OPTIMALISASI PENGOLAHAN SAMPAH ORGANIK DENGAN TEKNOLOGI BIODIGESTER SEBAGAI UPAYA KONSERVASI LINGKUNGAN

SELEKSI FITUR ALGORITMA NEURAL NETWORK MENGGUNAKAN PARTICLE SWARM OPTIMIZATION UNTUK MEMPREDIKSI KELAHIRAN PREMATUR

RANCANG BANGUN MEDIA BELAJAR FISIKA DASAR UNTUK MAHASISWA BERBASIS ANDROID

ANALISIS GLOBAL POSITIONING INFRASTRUKTUR DAN JARINGAN SOSIAL MEDIA DALAM BISNIS APLIKASI TRANSPORTASI DARAT ONLINE DI JAKARTA

PENGARUH INOVASI ANTENA PADA SIARAN TELEVISI MOBIL

PEMANFAATAN LIMBAH PEMBAKARAN BATUBARA (BOTTOM ASH) PADA PLTU SURALAYA SEBAGAI MEDIA TANAM DALAM UPAYA MENGURANGI PENCEMARAN LINGKUNGAN

PENERAPAN METODE GRAPHIC RATING SCALE (GRS) DALAM PENILAIAN KINERJA KARYAWAN

PEMBENTUKAN MODEL KLASIFIKASI DATA LAMA STUDI MAHASISWA STMIK INDONESIA MENGGUNAKAN DECISION TREE DENGAN ALGORITMA NBTREE

IMPLEMENTASI LOAD BALANCING DENGAN ALGORITMA EQUAL COST MULTI PATH (ECMP)

RANCANGAN SISTEM PENILAIAN HASIL KINERJA MULTI COMPANY DAN CROSS BUSINESS SECTOR 


\title{
ANALISA TAMAN ATAP DALAM UPAYA MENGURANGI LIMPASAN AIR HUJAN PADA BANGUNAN PERKOTAAN
}

\author{
${ }^{1}$ Endah Lestari; ${ }^{2}$ Irma Wirantina K; ${ }^{3}$ Ranti Hidayawanti \\ 12 s Jurusan Teknik Sipil, Sekolah Tinggi Teknik - PLN \\ Email: endah.lestari@gmail.com, irma_wirantina@yahoo.com,ranti3780@gmail.com
}

\begin{abstract}
ABSTRAK
Dengan meningkatnya kesadaran masyarakat pada sistem hubungan manusia dengan lingkungan sekitar, masyarakat mulai bergeser kepada arah sumber dan metode yang lebih baik dalam membantu perbaikan lingkungan. Salah satu metode yang mulai dimanfaatkan adalah penerapan konstruksi atap hijau. Ada banyak manfaat yang didapatkan untuk memasang atap hijau (green roof) apakah itu di bangunan rumah atau bangunan kantor. Penelitian dilakukan pada konstruksi atap hijau yang dapat diaplikasikan, manfaat dalam pemasangan atap hijau dan proses yang dijalankan untuk instalasi atap hijau dengan melakukan pendekatan konstruksi yang dapat diaplikasikan pada bangunan perumahan perkotaan di Jakarta dan pada analisis biaya pada kebutuhan material dan pemasangan. Dan dalam upayanya guna mengurangi limpasan air hujan. Atap hijau sebagai salah satu dalam pengelolaan air hujan di perkotaan. Dari hasil penelitian menghasilkan perhitungan pada lokasi survey prosentase penurunan limpasan $26 \%$. Sedangkan pada pengujian benda uji/mock-up terjadi pengurangan volume limpasan sejumlah 95\%. Dapat disimpulkan bahwa penggunaan taman atap/atap hijau dapat mengurangi volume limpasan yang dihasilkan oleh air hujan, sehingga limpasan air permukaan yang dihasilkan otomatis berkurang. Hal ini juga akan mengurangi beban drainase-drainase kota dalam menampung air. Taman Atap berperan pada manajemen pengelolaan air hujan guna menanggulangi genangan sampai pada bahaya banjir.
\end{abstract}

Kata kunci: Taman atap, Pengurangan Limpasan Hujan, Manajemen Air Hujan

\section{ABSTRACT}

With the increasing public awareness of the human relations system with the surrounding environment, communities are beginning to shift towards better sources and methods to help improve the environment. One of the methods that began to be utilized is the application of green roof construction. There are many benefits for installing a green roof whether it is in a home or office building. The study was conducted on applicable green roof construction, the benefits of installing a green roof and a process run for a green roof installation with a construction approach applicable to urban housing buildings in Jakarta and on cost analysis on material requirements and installation. And in its efforts to reduce rainwater runoff. Green roof as one in the management of rainwater in urban areas.

From the result of the research resulted the calculation on survey location percentage of runoff decrease $26 \%$. While in the test object / mock-up there is a reduction of $95 \%$ runoff volume. It can be concluded that the use of a green roof / roof garden can reduce the runoff volume produced by rainwater, resulting in reduced surface runoff automatically reduced. This will also reduce the drainage-drainage burden of the city in accommodating water. The Roof Garden plays a role in the management of rainwater management to cope with puddles up to the danger of flooding

Keyword: Roof Garden, Rainfall Surface Runoff, Rainwater Management

\section{PENDAHULUAN}

\subsection{Latar Belakang}

Vegetasi, terutama hutan, telah diidentifikasikan sebagai komponen penting dari strategi apapun untuk mengurangi emisi gas rumah kaca, melalui penyerapan karbon pada biomasa kayu pohon. Mengingat terbatasnya ruang yang tersedia, terutama di perkotaan besar, strategi adaptasi baru seperti menempatkan vegetasi langsung pada bangunan atap menjadi sangat menarik. Taman-taman atap atau taman hijau telah dikembangkan di beberapa negara di Eropa. Salah satunya di Canada telah terbukti dapat mengurangi gas rumah kaca sekitar $6 \%$ di sekitar tahun $2008-$ 2012. Dari penelitian tersebut atap hijau bisa merupakan solusi dari pengurangan efek gas rumah kaca.
Instalasi atap hijau memberikan beberapa keuntungan pada wilayah perkotaan. Atap hijau dapat meningkatkan kualitas lingkungan perkotaan (urban environment quality), dapat mengurangi energi panas pada proses pendinginan ruangan melalui penutupan pada atap, evapotranspirasi dan sebagai insulator panas.

Atap hijau merupakan tiruan dari kondisi penerapan ruang terbuka dalam menangkap air hujan pada saat musim penghujan. Efektifitas atap hijau dapat langsung berkorelasi dengan ketebalan dan sifat dari media tumbuh atap hijau. Alam pada batas tertentu dapat direplikasikan di atas bangunan tergantung pada seberapa kuat konstruksi atap. Alam bertindak seperti insulator yang perlahanlahan menyerap dan menahan energi dari sinar matahari lalu melepaskannya ketika udara lingkungan sekitar mendingin. Dengan atap hijau, 
atap bertindak sebagai baterai penyimpan panas dimana perlahan-lahan menyerap dan menahan sinar matahari dan melepaskannya disaat udara di sekitar mendingin. Penelitian di berbagai negara membuktikan bahwa penghematan energi akan maksimal didapatkan pada bangunan selama musim kemarau.

Penelitian juga menunjukkan bahwa pemakaian atap hijau belum sepenuhnya dapat dilaksanakan di beberapa negara maju terlebih lagi di negara-negara berkembang dikarenakan biaya konstruksi dan biaya pemeliharaan jangka panjang yang tinggi. Namun terdapat beberapa jenis atap hijau yang dapat ditinjau dan disesuaikan dengan iklim di daerah tersebut juga dari segi pembiayaannya.

Instalasi atap hijau merupakan solusi yang dapat digunakan untuk meningkatkan kualitas lingkungan perkotaan dan membantu meningkatkan manajemen air hujan di lingkungan perkotaan. Sebagian dari hujan disimpan dalam media tumbuh sementara dan akan diambil oleh tanaman dan kembali di atmosfer melalui evapotranspirasi. Atap hijau menunda air limpasan yang mengalir masuk ke dalam saluran-saluran kota, yang merupakan masalah yang signifikan bagi banyak kota-kota besar di dunia. Tanaman dan media tumbuh juga dapat menyaring polusi udara.

\subsection{Tujuan Penelitian} adalah:

Tujuan yang hendak dicapai dari penelitian ini

1) Mengetahui teknik-teknik konstruksi atap hijau dalam upaya mengurangi limpasan air permukaan.

2) Mengetahui teknik aplikasi atap hijau pada bangunan perkotaan.

3) Mengetahui pengaruh atap hijau dalam pengelolaan sumber daya air.

4) Memberikan alternatif pengelolaan sumber daya air.

\subsection{Batasan Penelitian}

Lingkup dan batasan dari penelitian ini adalah sebagai berikut:

1. Penelitian ini dilakukan pada bangunan rumah di Jalan Tangkuban Perahu no. 20 Jakarta Pusat

2. Fokus penelitian pada perhitungan limpasan yang terjadi setelah metode Taman Atap diterapkan pada hunian.

3. Pembuatan mock-up (contoh) konstruksi Taman Atap dengan pemakaian bahan-bahan yang banyak terdapat di sekitar rumah.

\section{METODOLOGI PENELITIAN}

Atap Hijau/Taman Atap atau lebih dikenal dalam bahasa Inggris Roof Garden atau Green Roof adalah ruang terbuka hijau yang dibuat dengan menambahkan lapisan tanaman di atas sistem atap. Lapisan sistem atap hijau dari atas ke bawah termasuk adalah sebagai berikut:

- Tanaman, biasanya dipilih tanaman khusus untuk aplikasi tertentu

- $\quad$ Sistem pengairan dan pengontrolan
- Media tumbuh rekayasa, bukan tanah

- Filter berupa kain, tempat akar, media tumbuh, memungkinkan untuk penetrasi air

- Lapisan drainase khusus, penampungan air yang dibuat khusus

- Lapisan mebran anti air

- Struktur atap, dengan insulator

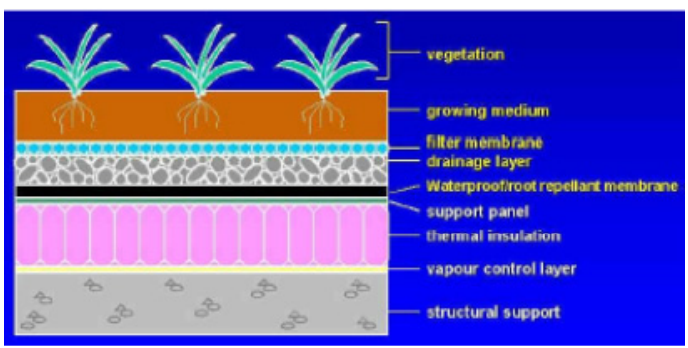

Gambar 1. Lapisan Sistem Atap Hijau

Persyaratan konstruksi khusus dan pertimbangan dalam mengembangkan taman atap.

- Perlindungan Atap dan Struktur

Unsur yang paling penting dalam pembangunan taman atap adalah melindungi integritas atap dan komponen struktur di bawah taman.

- $\quad$ Kapasitas Beban (Load Bearing Capacity)

Tenaga ahli harus memverifikasi kapasitas beban (load bearing capacity) maksimum yang dapat dipikul oleh struktur yang ada. Biasanya batas beban mati tambahan minimal adalah 150 psf antara kolom yang diperlukan untuk mengakomodasi pembangunan taman atap.

- $\quad$ Lapisan Tahan Air (Waterproofing)

Sistem waterproofing harus dipasang untuk melindungi struktur bangunan. Sebuah sistem waterproofing dipasang dengan baik dapat bertahan seumur hidup bangunan, namun bila ada kebocoran kecil dapat mengakibatkan perombakan seluruh taman untuk menemukan dan memperbaiki kerusakan.

- Ketentuan Penanaman

Konstruksi atap hijau dibuat terdiri dari lapisanlapisan. Kegagalan komponen tanaman dapat menyebabkan kerusakan yang cukup nyata dan membutuhkan biaya yang mahal untuk memperbaikinya.

- Saluran Air (Drainase)

Saluran air pada atap yang ada harus sesuai untuk digunakan dalam taman atap. Beberapa modifikasi diperlukan untuk mengakomodasi kebutuhan taman atap.

- Pertimbangan Iklim

Iklim dan paparan dapat menjadi faktor utama dalam keberhasilan ruang luar. Hal ini merupakan bahan pertimbangan dalam pemilihan bahan tanaman, tapi juga faktor penggunaan pada manusia dan kenyamanan.

- Kemiringan Atap

Dalam membangun taman atap sebaiknya tidak hanya dapat diaplikasikan pada atap datar atau dak beton, tetapi juga dapat diaplikasikan pada atap model pelana, atap perisai, atap limas, dan lain-lain. Kemiringan atap yang dianjurkan adalah di atas $10^{\circ}$ dan tidak lebih dari $45^{\circ}$. 


\section{Keuntungan Membangun Atap Hijau/Taman Atap}

Membuat atap hijau menghasilkan banyak keuntungan, baik di tingkat makro-seluruh kota dan mikro-bangunan lingkungan perumahan. Sistem atap hijau menyimpan sebagian besar dari curah hujan tahunan dan melepaskannya ke atmosfer dengan sistem transpirasi.

Beberapa manfaat pada tingkat makro adalah:

a. Mengurangi efek panas

Sebagian di kota-kota besar lahan terbuka telah tertutupi oleh lapisan tahan air, seperti jalan-jalan beraspal, atap-atap kota menyerap panas matahari dan memantulkannya kembali ke atmosfer sekitarnya. Tanaman menambah faktor pendinginan dengan melepaskan air melalui proses yang disebut evapotranspirasi.

b. Mengurangi polusi

Tanaman dapat mengurangi kadar $\mathrm{CO} 2$ pada kota-kota besar seperti Jakarta. Dengan banyaknya kendaraan yang ada kadar CO2 yang membuat polusi udara akan bertambah seiring dengan pertumbuhan perekonomian dalam suatu daerah.

c. Mengurangi limpasan

Air hujan yang dilimpaskan melalui atap rumah dan langsung mengalir ke dalam saluransaluran drainase kota lalu ke badan sungai. Mengalirkan air limpasan hujan langsung ke drainase kota membuat debit air hujan akan meningkat dan menyebabkan bertambahnya beban pada sungai kota.

d. Insulator bangunan

Seperti pengurangan efek panas, taman atap juga membawa manfaat sebagai isolasi bangungan. Ekstra lapisan di atas atap membantu melindungi bangunan, yang berarti pemanasan menjadi lebih rendah dan udara dalam bangunan menjadi lebih dingin.

\section{Limpasan dan Faktor-Faktor yang Mempengaruhi}

Limpasan adalah apabila intensitas hujan yang jatuh di suatu DAS melebihi kapasitas infiltrasi, setelah laju infiltrasi terpenuhi air akan mengisi cekungan-cekungan pada permukaan tanah. Setelah cekungan-cekungan tersebut penuh, selanjutnya air akan mengalir (melimpas) diatas permukaan tanah.

Komponen-komponen dari limpasan berasal dari tiga sumber yaitu:

1. Aliran Permukaan (surface flow) adalah bagian dari air hujan yang mengalir dalam bentuk lapisan tipis di atas permukaan tanah. Disebut juga aliran langsung (direct runoff). Aliran permukaan dapat terkonsentrasi menuju sungai dalam waktu singkat, sehingga aliran ini merupakan penyebab utama terjadinya genangan dan banjir.

2. Aliran Antara (interflow) adalah aliran dalam arah lateral yang terjadi di bawah permukaan tanah. Terdiri dari gerakan air dan lengas tanah secara lateral menuju elevasi yang lebih rendah, yang akhirnya menuju ke sungai. Prosesnya lebih lambat dari aliran permukaan, dengan tingkat kelambatan dalam beberapa jam sampai hari.
Aliran Air Tanah adalah aliran yang terjadi di bawah permukaan air tanah ke elevasi yang lebih rendah yang akhirnya menuju ke sungai atau langsung ke

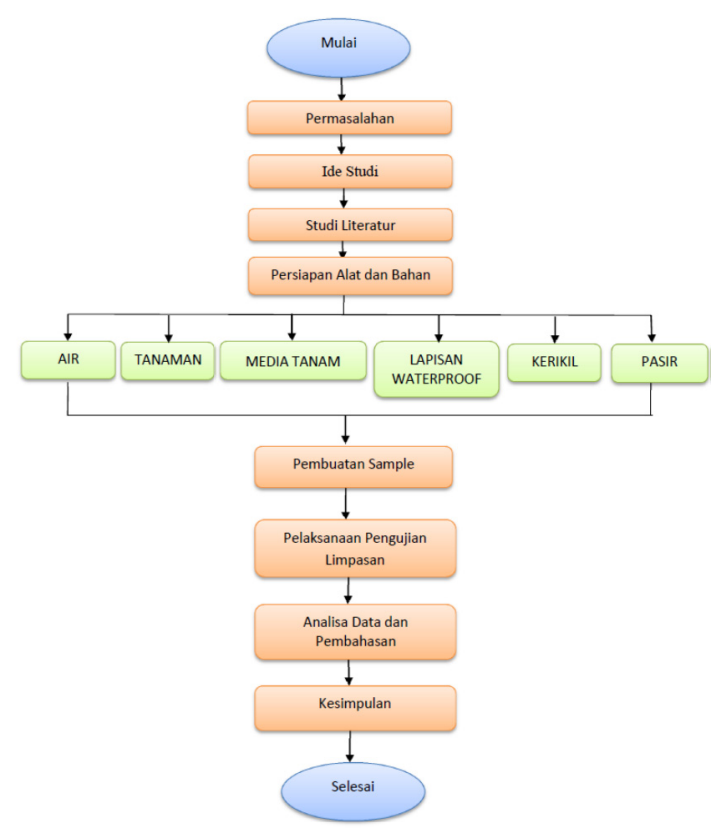

Gambar 2. Bagan Alir Penelitian

\section{HASIL PEMBAHASAN}

\subsection{Studi Kasus}

Penerapan konsep taman atap dalam mengurangi air limpasan belum banyak diaplikasikan pada hunian di kota-kota besar seperti Jakarta. Hal ini disebabkan karena kurangnya informasi mengenai kegunaan taman atap serta mahalnya biaya konstruksi dan pemeliharaan dari taman atap.

Rumah di Jalan Tangkuban Perahu, Guntur, Jakarta Pusat merupakan salah satu model hunian dengan konsep bangunan hijau yang salah satunya mengaplikasikan taman atap pada penutup atapnya. Selain berfungsi sebagai penghambat radiasi terhadap sinar matahari, taman atap pada hunian ini memberikan kestabilan suhu permukaan beton terhadap perbedaan temperatur siang dan malam hari. Hunian ini juga berupaya membuktikan bahwa penggunaan pendingin ruangan (Air Conditioning) tidak selalu diperlukan pada lingkungan seperti ini.

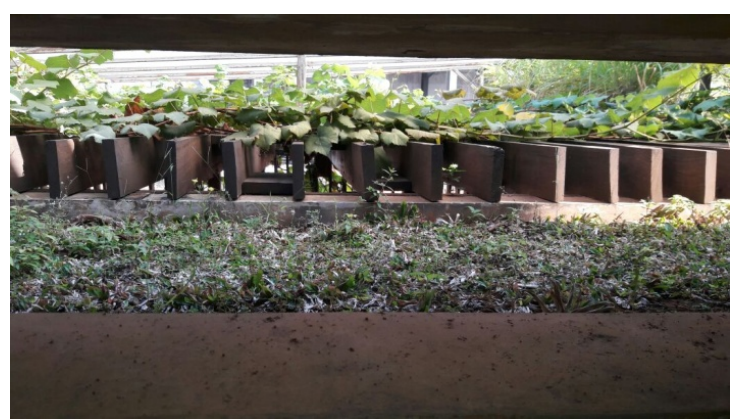

Gambar 3. Aplikasi Taman Atap dengan Tanaman Merambat dan Rumput 

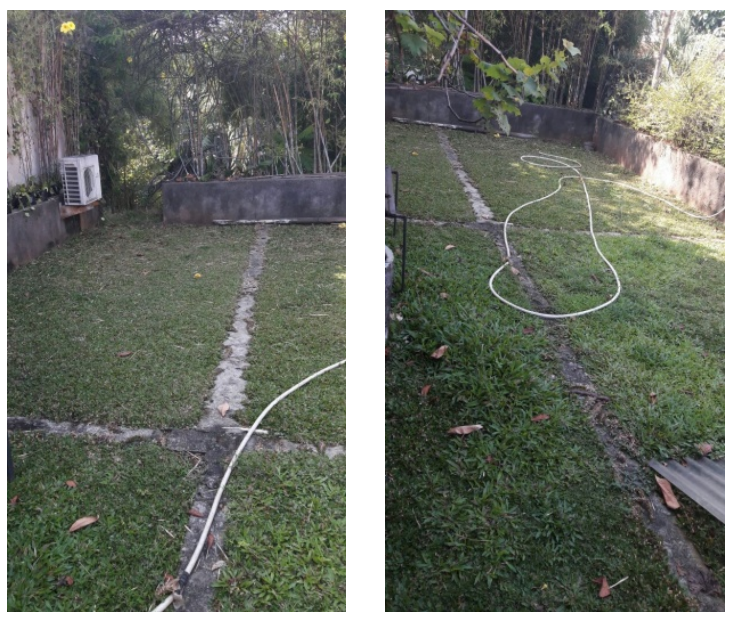

Gambar 4. Taman Atap pada Atap Dak Beton Lantai 1

Konstruksi atap dengan menggunakan atap beton dengan media tanah sebagai media tanam. Kedalaman media tanam $\pm 8-10 \mathrm{~cm}$ dengan jenis tanaman yang digunakan sebagian besar di seluruh atapnya adalah rumput gajah mini. Pada taman atap di hunian ini untuk jenis tanaman tinggi menggunakan media pot sebagai media tanam.
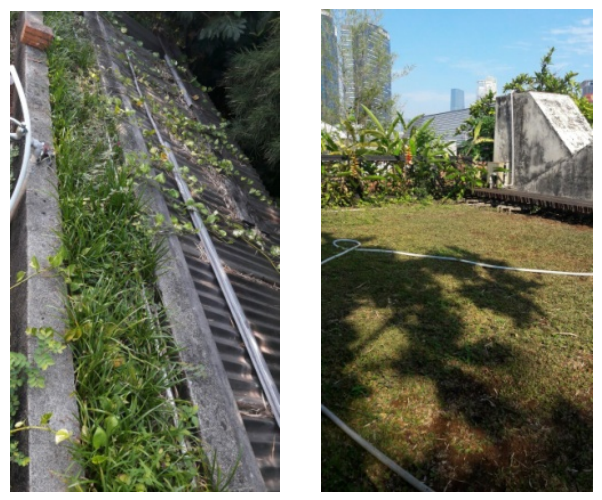

Gambar 5. Media Tanam Pot pada Taman Atap (kiri) Gambar 6. Taman Atap pada Atap Beton Lantai 2 (kanan)

Rumah dengan 2 lantai ini memiliki taman atap di kedua atap betonnya, pada atap lantai 1 dan atap lantai 2. Sehingga masing-masing lantai mendapatkan keuntungan dari taman atapnya salah satunya adalah menurunkan suhu di dalam ruangan akibat panas yang dihasilkan oleh sinar matahari.

Namun kekurangan dari taman atap di rumah ini adalah tidak adanya saluran drainase untuk buangan air dari sisa penyiraman media taman atap. Hal ini dikhawatirkan menimbulkan genangan air yang pada akhirnya dapat menyebabkan terjadinya rembesan bahkan kebocoran ke lantai bangunan.

Penggunaan media tanam dengan tanah, ketika harus disiram saluran endapannya akan menjadi berwarna coklat dan dapat membuat kotor lantai dak atas. Selain itu tanah juga mempunyai beban masa yang besar dan berat. Tanah juga dapat menyerap dan meneruskan panas dan lebih cepat terjadi penguapan sehingga tanah menjadi lebih cepat kering. Untuk itu perlu dikembangkan dengan menggunakan media tanam pengganti tanah yang lebih ringan, aspek perawatannya lebih mudah dan tidak mudah terjadinya penguapan.

\subsection{Pembahasan Hasil Penelitian}

Penelitian yang dilakukan penulis adalah pengaruh Taman Atap pada hunian perkotaan sebagai daerah resapan yang dapat mengurangi air limpasan dari hujan dan sebagai salah satu alat pencegah bahaya banjir. Menurut penelitian Taman Atap dapat mengurangi air hujan 50 - 90\%. Sebagian besar air akan melalui proses transpirasi dan evaporasi dan kelebihannya akan disimpan oleh media tanam untuk sementara waktu. Hal tersebut dapat mengurangi tekanan dari sistem pembuangan air melalui pipa pembuangan dalam tanah. Sebagai hasilnya pemilik rumah dapat memperkecil dimensi bahkan mengurangi penggunaan sistem pembuangan air melalui pipa pembuangan dan selokan.

Kombinasi antara roof garden dengan sistem pengelolaan air hujan modern contohnya tanki penyimpan air dan sumur resapan dapat mengalirkan air hujan secara keseluruhan ke area di bawah rumah melalui talang air. Hal ini akan menyebabkan hanya sedikit air yang perlu dialirkan ke selokan dan sungai.

\subsubsection{Pembangunan Atap Hijau/Taman Atap}

Berdasarkan banyaknya manfaat yang bisa diperoleh dari taman atap, sehingga perlu dikembangkan teknologi ini dan diaplikasikan pada hunian perkotaan. Berkaitan dengan aplikasi dan pembuatan taman atap tentulah memerlukan persyaratan konstruksi sehingga didapatkan taman atap yang tidak hanya indah namun juga aman baik bagi pengguna maupun bagi konstruksi bangunan di bawahnya.

Langkah-langkah yang dilakukan dalam pembangunan taman atap adalah sebagai berikut:

\section{Perlindungan yang Baik pada Atap dan Struktur}

Kapasitas beban yang ditopang oleh atap dapat direncanakan agar tidak melebihi kapasitas dari daya penahan beban yang dimiliki oleh atap. Dalam hal ini perlunya teknik-teknik perhitungan struktur yang baik dan cermat.

Sebaiknya sejak awal dibuat perancangan atap yang baik dalam pembangunan sebuah rumah atau bangunan lainnya. Perancangan atap terhadap daya tahan air untuk melindungi dari rembesan air. Lapisan atap dibuat miring untuk mengalirkan air sebagai sistem drainase permukaan. Harus dapat dipastikan kekuatan dari atap agar dapat mencegah biaya perbaikan jika terjadi kebocoran yang akan menyebabkan seluruh taman pada atap harus dibongkar untuk menemukan kebocoran tersebut. Meskipun awal dari kebocoran sangat kecil namun dapat berakibat terciptanya bukaan-bukaan air yang dapat dipenetrasi oleh akar tanaman. Akar tanaman dalam waktu lama akan membesar dan berakibat bertambah parahnya kerusakan terjadi pada atap.

\section{Sistem Drainase yang Baik dan Aman}

Dalam merencakan sistem drainase yang baik pada taman atap adalah dengan menggunakan 
sistem bersama dengan sistem drainase bagian bawah bangunan. Drainase pada taman atap dimaksudkan untuk dapat mengumpulkan air pada permukaan dan sub permukaan. Untuk mencegah media tanah masuk dan menyumbat drainase, media tanam harus dilengkapi oleh saringan/filter yang terbuat dari bahan polypropylene. Media tanam tidak boleh mengandung endapan lumpur karena dapat menyumbat saringan/filter dan berakibat dapat menutup saluran drainase. Setiap saluran dan pipa drainase yang ada di lapisan bawah taman atap harus terdata dengan baik untuk memudahkan pengontrolan dan pengecekan bila terjadi kerusakan, serta memudahkan pemeliharaan.

\section{Media Tanam yang Ringan}

Media tanam yang baik untuk taman atap adalah bahan yang ringan, mampu memberikan nutrisi bagi pertumbuhan tanaman dan memiliki struktur yang tetap namun tetap mudah untuk dialiri air. Campuran tanah, pasir dan kerikil serta pupuk cukup baik untuk menjadi media tanam. Media tanam dapat diganti dengan media lain seperti styrofoam untuk mengurangi kelebihan berat.

Lapisan vegetasi pada taman atap merupakan jenis tumbuhan yang menyebar secara horisontal karena lapisan tanah tipis tidak menunjang pertumbuhan secara vertikal.

\section{Adaptasi terhadap Cuaca}

Taman atap harus di desain untuk dapat mengikuti perubahan musim, misalnya curah hujan terbesar yang terjadi pada musim hujan harus dapat diprediksi dari awal sehingga pipa-pipa dan saluran drainase tetap dapat menampung kelebihan air tersebut.

Tanaman yang tinggi serta struktur vertikal seperti pagar,lampu taman harus didesain agar tahan terhadap terpaan angin yang kencang. Pemilihan jenis tanaman juga penting karena angin memberi pengaruh kekeringan pada material tanaman dan juga media tanah karena evaporasi yang tinggi.

Tanaman yang dipilih untuk ditanam pada atap bangunan adalah tanaman yang dapat tahan terhadap sinar matahari yang berlebih. Daerah dengan sinar matahari berlebih memerlukan air lebih banyak dikarenakan tingkat evaporasi yang tinggi. Untuk itu perlu ditambah dengan pembuatan naungan yang alami dan buatan sebagai solusi untuk mengurangi kehilangan air.

\section{Penyiraman pada Taman Atap}

Penyiraman dimaksudkan untuk mencegah kekeringan pada media tanaman dan kerusakan bahkan kematian pada tanaman. Pada taman atap yang cukup luas sebaiknya penyiraman dilakukan dengan menggunakan sprinkler bawah tanah yang bekerja secara otomatis. Selain itu dapat juga dilakukan dengan cara penyiraman manual yang sebaiknya dilakukan pada malam hari agar media tanaman tidak terlalu cepat kering.

Dalam hal ini ketersediaan air haruslah mencukupi untuk kebutuhan penyiraman tanaman, membersihkan permukaan atap dan kemungkinan bila terjadi kebakaran.

\section{Metode Pemasangan}

Pemasangan semua materi taman atap haruslah hati-hati agar tidak merusak lapisan membran tanah air maupun konstruksi bangunan.

\section{Kenyamanan dan Keamanan}

Dikarenakan lokasi taman atap yang berada di atas atap gedung atau bangunan rumah yang umumnya tinggi, maka haruslah diutamakan memperhatikan keamanan pengguna. Batas terluar dari taman atap tidak boleh sampai ke ujung atap, melainkan diberi jarak 2-3 meter. Batas terluar taman juga sebaiknya diberi railing atau pagar yang kuat dan cukup ketinggiannya.

\section{Pemeliharaan}

Pemeliharaan taman atap meliputi kegiatan penyiraman, pemupukan, pemangkasan pohon dan tanaman hias, penanaman ulang dan pengecekan serta perbaikan utilitas-utilitas yang ada di dalamnya.

Selain penyiraman dan pemupukan sesekali, taman atap yang baik adalah yang tidak memerlukan banyak perawatan.

\subsubsection{Perhitungan Debit Limpasan}

Seperti dijelaskan pada bab sebelumnya yang menjadi fokus pada penelitian ini adalah bahwa pembangunan dari taman atap dapat mengurangi limpasan air hujan, sehingga dapat mengurangi jumlah air kotor yang mengalir ke saluran drainase kota.

Pada penelitian ini akan dihitung jumlah limpasan yang didapat setelah pembangunan taman atap pada rumah di Jl. Tangkuban Perahu.

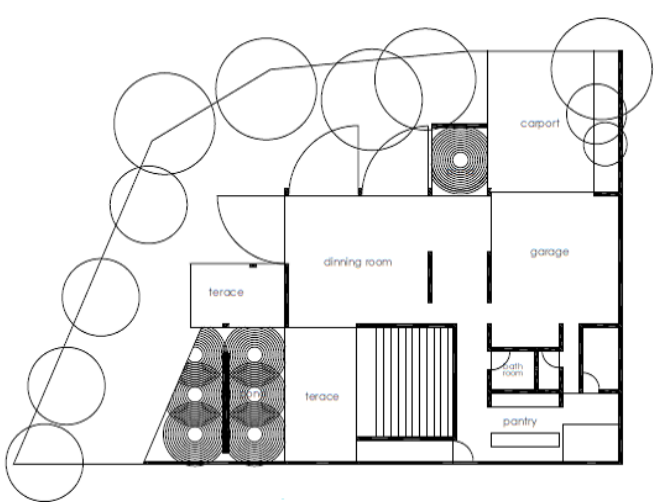

Gambar 7. Denah Lantai Dasar

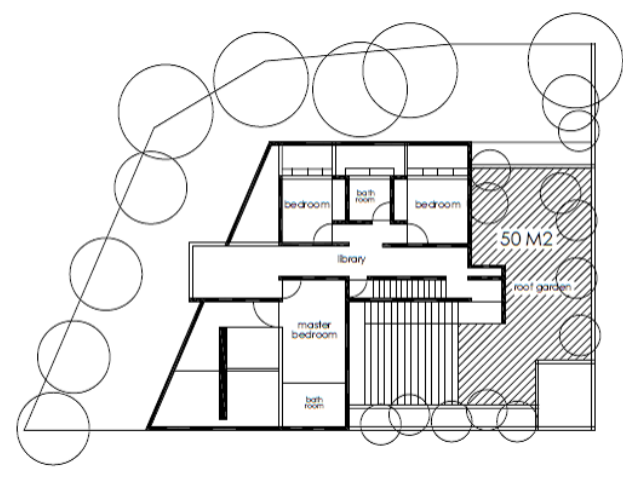

Gambar 7. Denah Atap Lantai Dasar 


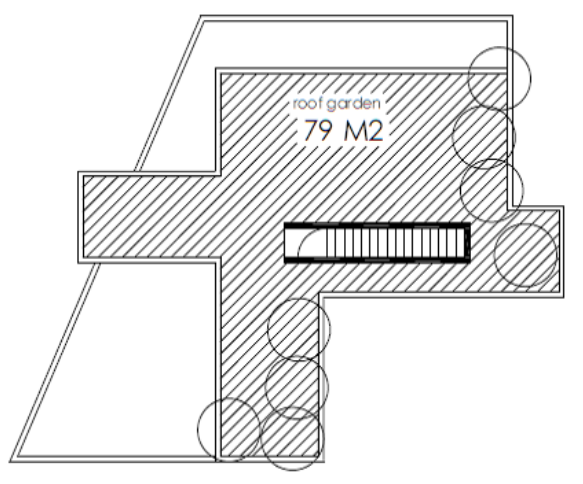

Gambar 8. Denah Atap Lantai 1

Perhitungan total area dari atap (catchment Area) $=79 \mathrm{~m}^{2}+50 \mathrm{~m}^{2}=129 \mathrm{~m}^{2}$

Perhitungan curah hujan yang jatuh rata-rata pada atap rumah. Daerah tangkapan hujan dianggap rata baik itu atap datar maupun atap miring. Dengan intensitas hujan rata-rata pada wilayah ini adalah $25 \mathrm{~mm} / \mathrm{jam}$ dengan lama hujan rata-rata 2 jam/1 kali hujan. Dalam hal ini memakai koofisien limpasan 0,95. Dengan perhitungan jumlah talang air adalah 1 buah. Maka volume air hujan rata-rata per hari adalah:

$V=\alpha . \beta . I . A . T$

$V=0,95 \cdot 1 \cdot 0,025 \cdot 129 \cdot 2$

$\mathrm{V}=6,128 \mathrm{~m}^{3}$ dalam 1 kali hujan

Areal atap yang tertutupi oleh taman pada bangunan ini adalah pada keseluruhan atap. Koofisien limpasan adalah 0,70 dengan asumsi ketebalan media tanam minimal 4 inch atau lebih. Sehingga dapat kita hitung volume air hujan yang dihasilkan pada atap dengan taman atap :

$$
\begin{aligned}
& V=\alpha \cdot \beta \cdot I \cdot A \cdot T \\
& V=0,70 \cdot 1 \cdot 0,025 \cdot 129 \cdot 2
\end{aligned}
$$

$\mathrm{V}=4,515 \mathrm{~m}^{3}$ dalam 1 kali hujan

Sehingga selisih volume air hujan sebelum ditutupi oleh taman dan setelah ditutupi oleh taman adalah: $6,128 \mathrm{~m}^{3}-4,515 \mathrm{~m}^{3}=1,613 \mathrm{~m}^{3}$

\subsubsection{Model Pengujian Konstruksi Atap Hijau/Taman Atap}

Konstruksi taman atap belum banyak digunakan di negara-negara berkembang seperti di Indonesia khususnya di Jakarta dikarenakan biaya konstruksi dari taman atap yang mahal selain material yang sulit didapatkan.

Oleh karena itu perlu dikembangkannya konstruksi taman atap yang dapat diaplikasikan di wilayah perkotaan di Jakarta dengan biaya yang terjangkau dan material yang mudah didapat di sekitar kita.

Pada penelitian ini akan dibuatkan mock-up (sample) dari konstruksi taman atap yang sederhana yang dapat dengan mudah diaplikasikan pada pemukiman-pemukiman setempat di daerah perkotaan. Ukuran mock-up dibuat dengan ukuran $50 \times 50 \mathrm{~cm}$.

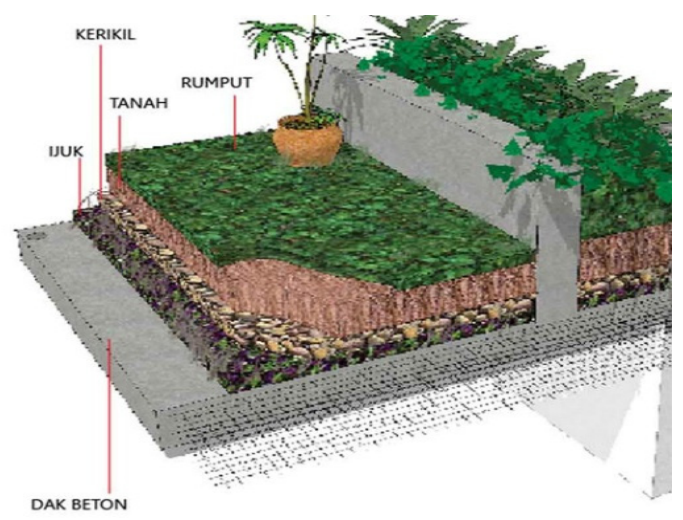

Gambar 9. Susunan Taman Atap

Urutan lapisan material yang digunakan untuk penelitian dari lapisan paling bawah sesuai dengan gambar 10 adalah sebagai berikut:

1. Lapisan Beton, yang merupakan penggambaran dari plat lantai. Pada percobaan penelitian ini dibatasi pada pengurangan jumlah limpasan bukan pada kekuatan dari plat lantai dengan taman atap, sehingga pada percobaan ini tidak menggunakan tulangan besi/baja yang biasanya digunakan sebagai elemen struktural plat lantai. Campuran beton yang digunakan adalah K175 dengan perbandingan Semen, Pasir dan Batu Split/Kerikil $1: 2: 3$.

2. Lapisan Water Proof, terdiri dari lapisan anti air berbentuk cairan diaplikasikan dengan pengecatan pada seluruh bagian permukaan dak beton. Dapat ditambah dengan lapisan anti air lain yang berupa lembaran serat fiber untuk lebih memperkuat agar tidak terjadi kebocoran pada plat lantai beton.

3. Lapisan ljuk, merupakan serat alami dari pohon aren yang tahan terhadap kelembaban dan air berfungsi sebagai penyaring kotorankotoran halus setelah lolos dari lapisan kerikil.

4. Lapisan Kerikil/Koral/Batu Split, digunakan untuk menyaring kotoran-kotoran kasar yang berasal dari air hujan.

5. Lapisan Media Tanam, yang terdiri dari tanah, sekam, kotoran kambing yang sudah dikeringkan dan pupuk. Pemakaian media tanam sangat dianjurkan agar tanaman dapat tumbuh dengan subur, dibandingkan bila menggunakan tanah saja.

6. Lapisan Rumput/Tanaman, dapat menggunakan rumput gajah mini atau rumput jenis lain yang dapat tahan terhadap panas sinar matahari langsung.

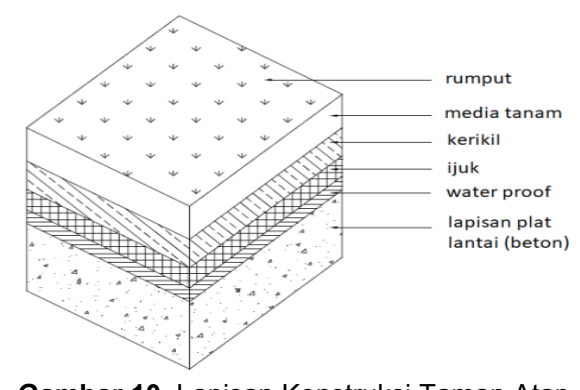

Gambar 10. Lapisan Konstruksi Taman Atap 


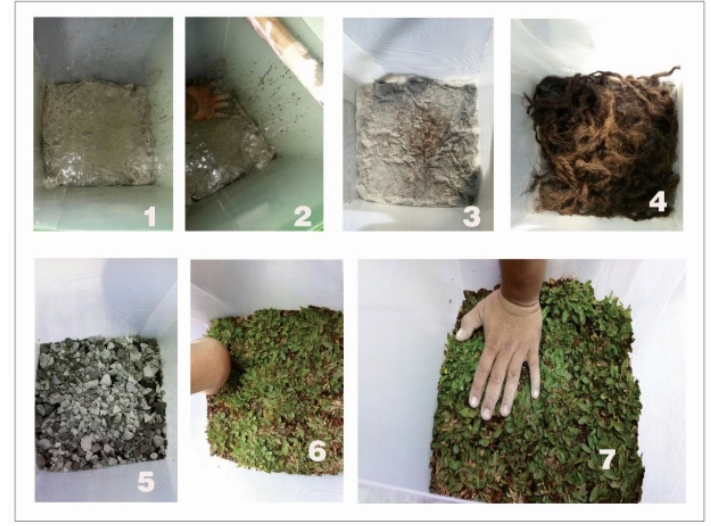

Gambar 11. Pembuatan Benda Uji/Mock-Up

\section{KESIMPULAN}

1. Dilakukan 2 (dua) jenis penelitian, yakni penelitian pertama dengan menggunakan metode perhitungan limpasan dengan merubah koofisien limpasan sebelum aplikasi atap 0,90 dan sesudah aplikasi taman atap 0,70 . Penelitian kedua dengan mengadakan percobaan langsung menggunakan benda uji/sample/mock-up.

2. Dari hasil penelitian pertama yang dilakukan, dengan perhitungan yang didapatkan pada lokasi survey di rumah Jalan Tangkuban Perahu terjadi pengurangan volume limpasan dengan jumlah total luasan atap $129 \mathrm{~m}^{2}$. Sebelum pengaplikasian taman atap didapatkan volume limpasan sejumlah $\mathbf{6 , 1 2 8}$ $\mathbf{m}^{\mathbf{3}}$ dalam 1 kali hujan. Setelah pengaplikasian taman atap dengan koofisien limpasan 0,70 mengakibatkan volume limpasan menjadi 4,515 $\mathrm{m}^{\mathbf{3}}$ dalam 1 kali hujan. Terjadi pengurangan limpasan sejumlah $1,613 \mathrm{~m}^{3}$ dengan prosentase berkurang sebesar $26 \%$.

3. Dari hasil penelitian kedua dengan menggunakan mock-up/contoh taman atap ukuran 50 × $50 \mathrm{~cm}$ disiram dengan $1000 \mathrm{ml}$ air dalam waktu 10 menit didapatkan volume hasil akhir setelah rembesan adalah $\mathbf{5 0} \mathbf{m l}$. Terjadi pengurangan volume sejumlah $950 \mathrm{ml}$ dengan prosentase berkurang sebesar $95 \%$.

4. Dari kedua penelitian yang dilakukan maka dapat disimpulkan terjadi perbedaan volume hasil akhir yang didapatkan setelah mengaplikasikan taman atap. Terjadi pengurangan volume runoff (limpasan) yang cukup besar pada pengujian langsung dengan benda uji/mock-up.

5. Material yang digunakan pada pengujian secara langsung dengan menggunakan benda uji/mock-up adalah material yang mudah didapatkan di daerah-daerah pemukiman di perkotaan. Sehingga pengaplikasian taman atap dapat dengan mudah dilakukan bagi masyarakat di kota.

6. Beberapa manfaat yang didapatkan dari Atap Hijau/Taman Atap, salah satunya adalah dapat mengurangi Surface Runoff (Air Limpasan Permukaan) yang dihasilkan oleh air hujan. Hal ini mengakibatkan volume air yang masuk ke dalam drainase kota berkurang dan juga mengakibatkan beban sungai/kali berkurang. Pengurangan air limpasan permukaan adalah salah satu cara dalam manajemen pengelolaan banjir.

\section{DAFTAR PUSTAKA}

Donnel, Noah Kilmer. Rooftop Gardens. A Green Solution to Los Angeles Urban Problems. USA.

Mc Caren Design, Inc. Design And Development of a Roof Garden.

Bizzari, Melissa and Friends. (2014). A Rooftop Garden at 129 Lake Street: A Feasibility Study of the Installation of a Green Roof on Brighton Campus.

Departement of Ecology State of Washington.(2012). Stormwater Management Manual for Western Washington.

Coombes, Peter J. (2000). Figtree Place: a case study in water sensitive urban development (WSUD) NWS, Australia.

Central New York Regional Planning \& Development Board.Green Stormwater Management: A New Way of Controlling Runoff. Newsletter.

Maryono, A, (2014). Menangani Banjir, Kekeringan dan Lingkungan. Yogyakarta: Gama Press.

Suripin, (2004). Sistem Drainase Perkotaan yang Berkelanjutan. Yogyakarta: Andi. 